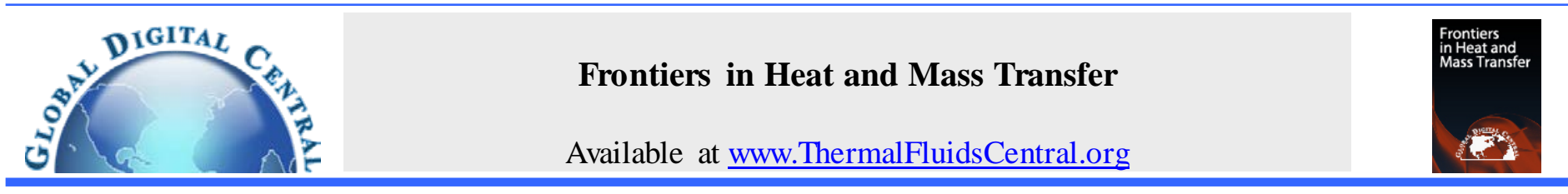

\title{
A TRIBUTE IN MEMORY OF DR. EDWARD THOMAS MAHEFKEY
}

\author{
B. Barthelemy ${ }^{1,2}$, J. Beam ${ }^{1}$, W. Borger ${ }^{1,3}$, M. Braydich ${ }^{1,4}$, L. Chow ${ }^{5 *}$, B. Donovan ${ }^{6}$, A. Faghri ${ }^{7}$, A. Garscadden ${ }^{1}$, D. Jacobson ${ }^{8}$, E. Kennel ${ }^{1,9}$, \\ J. Leland ${ }^{1,10^{*}}$, Q. Leland ${ }^{6}$, R. Ponnappan ${ }^{1,11}$, M. Ramalingam ${ }^{12}$, T. Reitz ${ }^{6}$, R. Rivir ${ }^{1}$, B. Tsao ${ }^{10}$, V. Van Griethuysen ${ }^{6}$, K. Yerkes ${ }^{6}$ \\ ${ }^{1}$ Air Force Research Laboratory (former or retired) \\ ${ }^{2}$ Wright Brothers Institute \\ ${ }^{3}$ WU Borger Consulting \\ ${ }^{4}$ Aerospace Business Development Associates, Inc. \\ ${ }^{5}$ University of Central Florida \\ ${ }^{6}$ Air Force Research Laboratory \\ ${ }^{7}$ University of Connecticut \\ ${ }^{8}$ Arizona State University \\ ${ }^{9}$ Applied Sciences, Inc. \\ ${ }^{10}$ University of Dayton Research Institute \\ ${ }^{11}$ Air Force Office of Scientific Research \\ ${ }^{12}$ Universal Energy Systems, Inc.
}

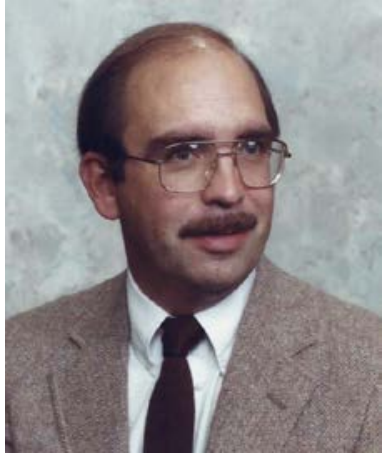

On April 26, 2014, the aerospace power, thermal management and energy conversion community lost a very dear colleague, Dr. Edward Thomas (Tom) Mahefkey. He passed away in Flowery Branch, Georgia at the age of 73. Tom received his BS degree in 1961 from St. Louis University; an MS in Physics in 1970 and a PhD in Mechanical Engineering in 1977, both from University of Dayton. After 33 years as a project engineer, scientist and advanced development program manager, Tom retired from the Air Force Research Laboratory (AFRL) in 1995 at the level of Deputy Division Chief for Technology of the Propulsion Laboratory's Aerospace Power Division. He was internationally recognized in the fields of heat transfer and energy conversion. He had over 50 journal or symposium papers, including three best paper awards from AIAA and ASME. He also authored numerous technical reports on aircraft and spacecraft heat transfer and energy conversion applications and held of eight US patents.

Tom's many notable career accomplishments include his: being instrumental in establishing the AFRL Thermal Energy/Heat Pipe and the Thermionics laboratories, appointment as a science and technology agent for the Strategic Defense Initiative in 1983, appointment as Chair of the National Research Council on thermionic energy conversion in 1990, and chair of the ASME Energy Conversion Technical Committee from 1991to 1993. Tom was also an experienced educator, having held the rank of adjunct professor of mechanical engineering at the University of Dayton, Wright State University, University of Kentucky,
Ohio State University and the Air Force Institute of Technology; and the rank of research professor at the University of Central Florida's Mechanical and Aerospace Engineering Department.

Tom had a strong scientific curiosity and remained very active after his retirement. From 1995 to 2002, he consulted in his fields of expertise for several US research and development firms. During his time with the University of Central Florida (2002-2010) he worked closely with AFRL's Aerospace Power Division to identify solutions to emerging military aircraft thermal management issues. His studies showed that the majority of issues could be traced to inadequate heat sink conditions and his resulting recommendation that active refrigeration methods be developed was implemented. This led to his invited lecture in 2004 to the Office of Secretary of Defense JASON Aircraft Thermal Management Study Group to provide input on future USAF aircraft. During this period he also identified the potential and limits of novel chemisorption heat pipe combined cycle devices, a concept he originated. Perhaps Tom's most invaluable contribution was his mentorship of the next generation of researchers that will carry forward the research agenda that he helped shape.

Early in his career, Tom made significant contributions in shaping US power and energy system research. During the 1960's space race, development of decaying radio-isotope and nuclear fission based power systems was begun to expand capabilities beyond photovoltaic solar arrays and rechargeable battery systems. Aircraft power systems

*Corresponding authors. Email: Louis.Chow@ucf.edu; John.Leland@udri.udavton.edu 
became more complex and work on fuel cells, advanced batteries and alternative energy systems was begun. The 1970's ushered in the development of directed energy weapons and programs in magnetohydrodynamic generators, very large inductor and capacitor energy storage, and regenerative thermal energy systems were initiated to power these new weapons. The breadth and depth of United States Air Force (USAF) power and energy systems was vast and very complex and Tom recognized that a technical and investment strategy to guide research and development was desperately needed.

To create a sound basis for a strategy, Tom analyzed the proposed systems in great detail and created an elegant approach to guide the selection of power and energy systems for USAF applications. Over a three year period, he compiled the first comprehensive technical report on all current and potential USAF power and energy systems. This report was used for several decades as the starting point for the analysis and selection of key technologies for development and application. During this time, he also accomplished pioneering research on advanced energy conversion (thermoelectric and thermionic) and thermal management systems. By the end of the 1970s, development of alternative terrestrial power became a major USAF initiative which Tom guided and directed well into the 1980s. Tom's technical contributions, wise guidance and thorough analytical and experimental skills were critical to the success of major Air Force power and energy programs of the 1960s and 1970s. He was the singular force behind many major technical decisions of that time period and his work provided the foundation for the USAF's dominance in space.

Tom's systems approach had a particularly strong influence on Department of Defense (DoD) space nuclear power programs. Although solar photovoltaic energy conversion was the mainstay of USAF space power, nuclear reactor power could provide more power and better threat survivability to meet the growing demands of surveillance and other spacecraft. The US and the USSR both tested small nuclear reactors for spacecraft in the 1960's. The Atomic Energy Commission's (AEC) Systems for Nuclear Auxiliary Power (SNAP) program successfully flew the first space nuclear reactor, the SNAP$10 \mathrm{~A}$ in 1965, and despite many years of ambitious research projects, the next major initiative would not occur until the late 1970s. In 1975, the DoD and Energy Research \& Development Administration (formed from the the AEC and made a part of the Department of Energy (DoE) in 1977) created a joint steering group to explore space nuclear reactor concepts to meet DoD missions. Based on the work of this group, the DoE initiated the Space Power Advanced Research (SPAR) program in 1979 to meet requirements in the 10 to $100 \mathrm{~kW}$ range. Tom found that the size of the radiator became a dominant design factor at these power levels and showed that high heat rejection temperatures might be more desirable than high energy conversion efficiency, for maximum performance with minimum weight and deployed surface area. Thus, Tom suggested high temperature systems, such as thermionic energy conversion, would be preferred over lower temperature Rankine cycle based systems. He further recommended the use of liquid metal heat pipes to achieve high temperature isothermal heat rejection and the added advantage of considerably better reliability over dynamic cooling systems with their moving parts and wear surfaces.

This advice was controversial, however, and with NASA's funding of the SPAR program in 1981 (which was subsequently renamed SP100 ), thermoelectric energy conversion (despite its lower efficiency and lower heat rejection temperature) became the baseline design because the development of a thermionic nuclear reactor was considered to be decades away from practical demonstration. Undeterred, Tom initiated many programs to further mature thermionic energy conversion and liquid metal heat transfer technologies. Unbeknownst to the SP-100 thermoelectric power champions, the USSR was actively developing a thermionic space nuclear reactor system. Tom would eventually be proven right, ironically by the USSR, when in 1989 it announced that it had successfully flown two thermionic nuclear reactor spacecraft (commonly referred to as TOPAZ-2 or Thermionic Experimental Conversion in the Active Zone) two years earlier.
In a televised address to the nation on March 23, 1983, U.S President Ronald Reagan proposed what became the Strategic Defense Initiative (SDI), a defensive counter to the Soviet Union's rapidly growing arsenal of ballistic nuclear missiles. The SDI concept was immediately controversial and was hotly debated not only for its potential impact on diplomacy, but on its effectiveness as a defense system and its technical feasibility. The AFRL, Aerospace Power Division, originally stood up to develop The US response to Sputnik, was an obvious source of technical expertise to begin determining the feasibility of the SDI concept. Tom became the principal lead for SDI research performed by the USAF. Despite the politically contentious nature of the program and powerful influence of interests outside of the DoD, Tom never wavered in his belief that research should be pure of such considerations or influence, and maintained the highest degree of objectivity and integrity for SDI research programs.

Until SDI, the US had all but given up on land or sea based antiballistic missile (ABM) programs because they had proven to be technically challenging, impractical and easily countered. However, a space based system could counter a ballistic missile threat early in its boost phase before its multiple war heads or decoys were released and when its infrared signature, vital to tracking it, was greatest. While the scope of the problem was greatly simplified, the complexity of a space system far exceeded that of a terrestrial based ABM system and thus, system feasibility became the key question. There were numerous technical approaches proposed (nuclear powered X-ray lasers, chemical lasers, particle beams, kinetic projectiles or interceptors, etc.) most of them requiring platform power levels at least three orders of magnitude greater than anything previously launched. Along with these extraordinary power level challenges came the need to: dissipate equally large amounts of heat over a very short period of time, store large volumes of cryogens on orbit for many years, transport heat over a wide range of temperatures and at very high fluxes, and transport and mix cryogens or reactants under highly dynamic conditions.

Tom and his research group led numerous architecture studies that identified the developments necessary to make each technical approach feasible. Thorough and sound technical analyses allowed program officials to quickly discard approaches that were deemed impractical and to focus on more promising technologies. This was quite an achievement in such a politically charged environment heavily influenced by parochial interests. Undoubtedly, it would not have been possible without the unassailable analyses of Tom and his group.

Tom also created an extraordinarily collegial environment among external research organizations. Normally very competitive and highly protective of any advantage they might have, these universities, small businesses, aerospace companies and other government agencies came together to coordinate, identify and prioritize research initiatives under Tom's leadership. From this dynamic research community came advances in heat pipes, capillary pumped loops, high heat flux cooling, novel refrigerants, vapor cycle compressors, thermal energy storage materials, and high conductivity materials to name a few. Many of these technology developments have subsequently made their way into military and commercial vehicles, electronics, power systems and heat and ventilation systems as well as onto the Space Station.

In the late 1980s and at the height of the SDI program, Glasnost was introduced by Mikhail Gorbachev and the USSR's so called Iron Curtain began to be lifted. Tom was part of very a small group of DoD officials that seized the opportunity to reach out to USSR counterparts. Tom's collegiality toward scientists and engineers of the US's primary adversary created many lasting relationships that surely had a profound effect on the relationship between the two countries. As these relationships grew, the SDI program office and USAF arranged for a model of a TOPAZ-2 thermionic nuclear reactor satellite to be shown at the 1991 Space Nuclear Power Symposium in Albuquerque NM. The TOPAZ-2 thermionic energy technology that Tom had so strongly advocated for over ten years captured the attention of high level DoD officials. DoD funding of the SP-100 program ceased later that year (ultimately leading to the program's demise) and the DoD subsequently 
arranged to buy two working (sans fissile material) TOPAZ-2 spacecraft from the USSR. Ultimately, six TOPAZ-2 systems were purchased and extensively tested by the DoD. During this period, Tom also supported a number of visiting researchers from the USSR. They brought with them advanced porous sintered metal technology which could enable higher performance heat pipes and capillary pumped loops. Several of these researchers immigrated to the US and continue to contribute to the US technology base.

The impact of the SDI program on the end of the Cold War has been widely debated. Perhaps the most telling evidence of its impact came from Genrikh "Henry" Aleksandrovich Trofimenko, a long-time chief analyst at the Russian Academy of Science's Institute for the U.S. and Canada Studies, and author of the 1987 book, "The US Military Doctrine," who said, "Ninety-nine percent of the Russian people believe that you won the Cold War because of your President's insistence on SDI." While a decisive conclusion on SDI's impact will be left to future historians, many now agree that indeed, it hastened the end of the Cold War. Certainly, Tom is one of the Cold War's unsung heroes for guiding DoD research to make outstanding technical achievements against daunting technical and political challenges.

Dr. E. Thomas Mahefkey's technical leadership most importantly inspired a generation of new researchers and allowed numerous entrepreneurial small businesses to develop into thriving entities. His legacy includes the contributions of these individuals who continue to develop and demonstrate power, energy and thermal control technologies to meet aerospace and defense needs. 